\title{
ANTIFILARIAL EFFECT OF ARTEMISIA NILAGIRICA EXTRACT AND ITS ULTRA HIGH DILUTIONS AGAINST CANINE DIROFILARIASIS
}

\author{
Nirmal Chandra Sukul, Paromita Sarkar, Anirban Sukul \\ AND SANTi PRASAD SinHababU \\ Received May 12, 1999/Accepted June 21, 1999
}

\begin{abstract}
An ethanolic extract of the flowering meristems of worm wood, Artemisia nilagirica was allowed to evaporate. The residue, thus obtained, was administered orally on 4 pariah dogs naturally infected with Dirofilaria immitis at $10 \mathrm{mg} / \mathrm{kg} /$ day for 15 days and then at $20 \mathrm{mg} / \mathrm{kg} /$ day for the next 15 days. Two homoeopathic potencies of the A. nilagirica extract, called Cina 200 and Cina 1000, were obtained commercially and administered orally at $0.1 \mathrm{ml} / \mathrm{dog} /$ day for 30 days on two separate batches, each consisting of 4 dogs. Blood was sampled from the dogs before treatment and on day 15, 30, 45 and 75 following the treatment. A. nilagirica extract (Cina $\theta$ ) was diluted with $90 \%$ ethanol $1: 100$ and shaken by 10 manual strokes to prepare the 1st potency, called Cina 1 . All subsequent potencies were prepared by mixing 1 part of the preceding potency with 99 parts of $90 \%$ ethanol and giving the mixture 10 manual strokes. Cina $\theta$, Cina 200 and Cina 1000 reduced microfilarial densities in treated dogs by 78.38, 63.06 and $71.40 \%$, respectively on day 30 . There were $57.13,42.44$ and $64.20 \%$ reduction on day 75 . No apparent toxic effect was observed in the treated dogs. Electronic spectra of Cina $\theta$, Cina 200 and Cina 1000 showed comparable absorbance with the latter two giving a blue shift. Cina $\theta$ in $\mathrm{CCl}_{4}$ showed a red shift suggesting molecular complexation and charge transfer (CT) interaction between aqueous ethanol and compounds of $A$. nilagirica. CT was further evidenced by the NMR spectra of the deuterium nuclei of Cina $\theta$ in $90 \%$ ethanol. NMR spectra of Cina $\theta$, Cina 200, Cina 1000 and $90 \%$ ethanol indicated a change in the solution structure of Cina 200 and Cina 1000. This altered solution structure is thought to be responsible for inducing immune reaction of the hosts against the parasite.
\end{abstract}

Key words: Artemisia nilagirica, Antifilarial, Dirofilaria immitis, Homoeopathic potency, Ethanol solution structure, Electron transfer

\section{INTRODUCTION}

Species of Artemisia have long been used by rural people for expelling intestinal nematodes (Singh et al., 1983). High dilutions of the ethanolic extract of the flowering meristems of Artemisia nilagirica (Clarke) Pamp have been used in the Homoeopathic system of medicine under the name Cina against intestinal worms (Kent, 1911; Boericke, 1927). The purpose of the present study is to see whether this plant extract, both in its crude form and also its homoeopathic dilutions, called potencies, is effective against canine dirofilariasis.

In Homoeopathy the ethanol extract of $A$. nilagiri$c a$, called Cina $\theta$, is diluted with $90 \%$ ethanol $1: 100$ and the mixture is shaken with 10 powerful downward strokes to prepare the first centesimal potency called Cina 1. All subsequent potencies are prepared by adding to one part of the preceding potency 99 parts of $90 \%$ ethanol and shaking the mixture in a similar way (Anonymous, 1920; Sukul and Klemm, 1988). Effective homoeopathic potencies could also be produced by sonication instead of mechanical agitation (Sukul et al., 1996; Sukul, 1997). Two potencies of Cina, like Cina 200 and Cina 1000, purchased from King \& Co., Calcutta, were used. Since these potencies are too dilute to have any drug molecules, electronic and NMR spectra of them were obtained to find out their difference from the solvent medium like $90 \%$ ethanol vis-a-vis the physical basis of their effectiveness. In order to find out the solvent effect on the solute, we prepared Cina $\theta$ in a neutral solvent like $\mathrm{CCl}_{4}$ and obtained the electronic spectra of the solution.

Department of Zoology, Visva Bharati University, Santiniketan 731 235, West Bengal, India

Fax. 0091346353166 


\section{MATERIALS AND MethodS}

\section{Treatment with Cina $\theta$}

Cina $\theta$, purchased from King \& Co., Calcutta was allowed to evaporate in an incubator at $40^{\circ} \mathrm{C}$. The residue was dehydrated in a vacuum dessicator over anhydrous Calcium Chloride and stored at $4^{\circ} \mathrm{C}$. Blood was sampled from 4 naturally infected dogs, 2 males and 2 females, every 15 days for a period of 2 months and microfilarial concentration per $\mathrm{m} l$ of blood was determined. Blood film was allowed to dry, dehaemoglobinised in distilled water and stained with Giemsa stain. The same dogs were then administered orally with the residue of Cina $\theta$ at $10 \mathrm{mg} / \mathrm{kg}$ body weight/day for 15 days. Blood was sampled from the dogs on day 15. The same dogs were treated again orally with the residue at $20 \mathrm{mg} / \mathrm{kg} /$ day for 15 days more. Blood was sampled on day 30, 45 and 75. Capsules were filled with the residue, kept inside a loaf of bread and then offered to the microfilaraemic dogs.

\section{Treatment with Cina 200 and Cina 1000}

Blood was sampled from a batch of 4 infected dogs, 2 males and 2 females, every 15 days for 2 months. Cina 200 was mixed with pure cow milk at $0.1 \mathrm{ml} / 4 \mathrm{~m} l$ of cow milk and $4 \mathrm{~m} l$ of the mixture was offered in a glass plate to a dog which immediately consumed the mixture. The schedule of treatment and blood sampling were the same as with Cina $\theta$. However, the dosage of Cina 200 was same in the 2 phases of treatment. A batch of 4 naturally infected dogs (3 females and 1 male) was treated with Cina 1000 after determining the mf density for 2 months. The treatment schedule, dosage of the drug and blood sampling were same as with Cina 200.

\section{Electronic spectra of drug}

Using a UV-VIS spectrophotometer (Beckman DU 640) absorption spectra of Cina $\theta$ in $90 \%$ ethanol and Cina $\theta$ in carbon tetrachloride, Cina 200 and Cina 1000 against the corresponding solvent blanks were obtained in the wave length range of $190-750 \mathrm{~mm}$ at $29^{\circ} \mathrm{C}$. The spectra were run in matched quartz cuvettes and were corrected for instrumental baseline errors. Test solutions were kept at the above temperature for at least 10 min to allow for the thermal equilibration.

\section{NMR Spectra of drugs}

The spin-lattice relaxation time $\left(\mathrm{T}_{1}\right.$ in $\left.\mathrm{msec}\right)$ of the naturally abundant ${ }^{2} \mathrm{H}(0.015 \%)$ was measured in $90 \%$ ethanol, Cina $\theta$ in $90 \%$ ethanol, Cina 200 and Cina 1000 using a AMX-400 NMR spectrometer operating at 61.4
$\mathrm{MHz}$ at $22^{\circ} \mathrm{C}$. The mechanism by which excess spin energy of a nucleus (here ${ }^{2} \mathrm{H}$ ) is shared with the surroundings is referred to as the spin lattice relaxation. The time taken for a fraction $1 / \mathrm{e}=0.37$ of the excess energy to be dissipated is called the relaxation time. Such relaxation comes about by lattice motions like molecular tumbling in liquids (Banwell and McCash, 1994). Deuterium is a quadrupolar nucleus having a small quadrupole moment 1. Quadrupolar relaxation depends upon the interaction of the electric quadrupole moment with an electric field gradient. If the quadrupole moment is small, as it is for ${ }^{2} \mathrm{H}$, the interaction is small and the relaxation will be slow. Like all quadrupolar nuclei its relaxation is sensitive to $\tau_{\mathrm{c}}$. $\tau_{\mathrm{c}}$ is the average time taken to rotate through 1 radian or roughly the reciprocal of the rate of tumbling of the relevant piece of the molecule (Sanders and Hunter, 1993). $T_{1}$ values of ${ }^{2} \mathrm{H}$ of water, hydroxyl, methylene and methyl groups of ethanol were measured from the stacked spectra with the help of a computer.

\section{RESULTS}

\section{Treatment effect on mf count}

The mean microfilarial counts per $\mathrm{m} l$ of blood in 3 batches of dogs before treatment are shown in Table 1. The microfilarial concentration in each dog did not vary appreciably during the 2-month period of observation.

Table 1 Microfilarial concentration/ $\mathrm{m} l$ blood of dogs naturally infected with Dirofilaria immitis before treatment

\begin{tabular}{lrrrrc}
\hline \multicolumn{5}{l}{ Microfilarial concentration/m $l$ blood on different days } \\
\hline Dogs & Day 0 & Day 15 & Day 30 & Day 45 & Day 60 \\
\hline Batch I & & & & & \\
Male & 1,001 & 973 & 945 & 997 & 986 \\
Male & 437 & 423 & 480 & 505 & 440 \\
Female & 727 & 798 & 756 & 704 & 692 \\
Female & 813 & 852 & 808 & 826 & 874 \\
\hline Batch II & & & & & \\
Male & 219 & 241 & 264 & 313 & 274 \\
Male & 304 & 298 & 253 & 221 & 234 \\
Female & 535 & 477 & 542 & 580 & 569 \\
Female & 330 & 374 & 385 & 423 & 450 \\
\hline Batch III & & & & & \\
Male & 274 & 235 & 252 & 300 & 302 \\
Female & 236 & 287 & 259 & 247 & 272 \\
Female & 218 & 269 & 254 & 219 & 203 \\
Female & 251 & 275 & 244 & 235 & 279 \\
\hline Batc I: Treated
\end{tabular}

Batch I: Treated later with Cina $\theta$

Batch II: Treated later with Cina 200

Batch III: Treated later with Cina 1000 


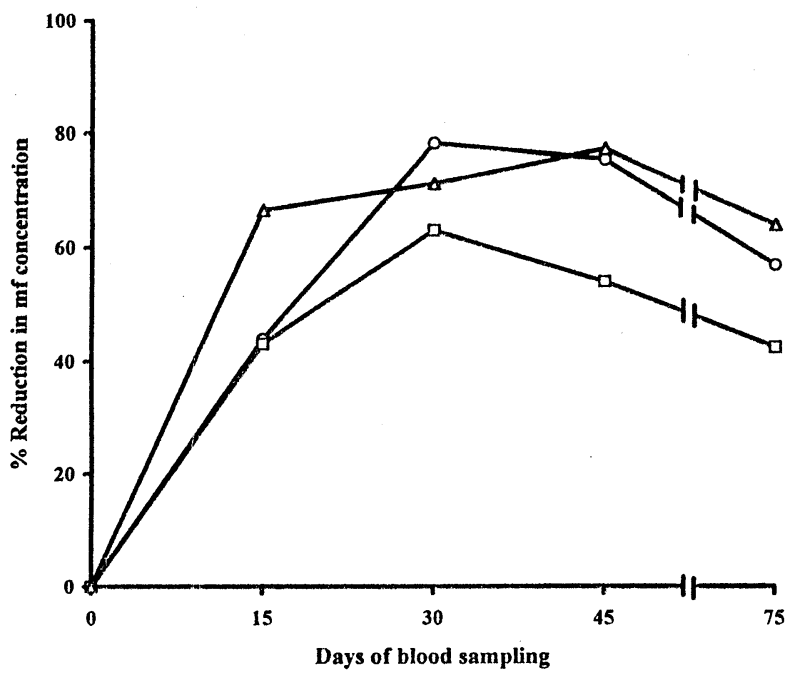

Figure 1 Percentage of reduction in microfilarial concentration of $D$. immitis in 4 dogs treated with ethanol extract of Artemisia nilagirica (Cina $\theta$ ) at $10 \mathrm{mg}$ / $\mathrm{kg} /$ day for 15 days and $20 \mathrm{mg} / \mathrm{kg} /$ day for the next 15 days (-O-). The same in 2 nd batch of 4 dogs treated with Cina 200 for 30 days ( $-\square-$ ) and in 3rd batch of 4 dogs treated with Cina 1000 for 30 days $(-\triangle-)$.

Percentage changes in microfilarial concentration for the treated dogs were plotted in a graph against days of sampling in Fig. 1. The mean mf density just before treatment of the 3 treatment groups served as the standard with respect to which the percentage change was

Table 2 Spin-lattice relaxation time $\left(\mathrm{T}_{1}\right)$ of ${ }^{2} \mathrm{H}$ of $90 \%$ ethanol, Cina $\theta$ in $90 \%$ ethanol, Cina 200 and Cina 1000. Cina $\theta$ is the ethanolic extract of $A$. nilagi. rica flowering tops. The two potencies, Cina 200 and Cina 1000, were prepared by successive dilution of Cina $\theta$ with $90 \%$ ethanol 1:100 and manual succussion. Measurements were taken by a AMX $-400 \mathrm{NMR}$ spectrometer operating at $61.41 \mathrm{MHz}$ at $22^{\circ} \mathrm{C}$

\begin{tabular}{|c|c|c|c|c|}
\hline & \multicolumn{4}{|c|}{ Mean \pm S.E. of $T_{1}(\mathrm{~m} \mathrm{sec})$} \\
\hline & \multirow{2}{*}{$\frac{\text { Water }}{\mathrm{OH}}$} & \multicolumn{3}{|c|}{ Ethanol } \\
\hline & & $\mathrm{OH}$ & $\mathrm{CH}_{2}$ & $\mathrm{CH}_{3}$ \\
\hline Ethanol 90\% & $\begin{array}{r}106.9 \\
\pm 0.5 \mathrm{a}\end{array}$ & $\begin{array}{r}110.8 \\
\pm 0.8 \mathrm{a}\end{array}$ & $\begin{array}{r}846.5 \\
\pm 0.4 \mathrm{a}\end{array}$ & $\begin{array}{r}822.5 \\
\pm 0.5 \mathrm{a}\end{array}$ \\
\hline $\begin{array}{l}\text { Cina } \theta \text { in } 90 \% \\
\text { EtOH }\end{array}$ & $\begin{array}{r}104.3 \\
\pm 0.4 \mathrm{~b} \\
\end{array}$ & - & $\begin{array}{r}883.4 \\
\pm 0.3 \mathrm{~b} \\
\end{array}$ & $\begin{array}{r}776.1 \\
\pm 0.4 \mathrm{~b} \\
\end{array}$ \\
\hline Cina 200 & $\begin{array}{r}108.2 \\
\pm 0.7 \mathrm{c}\end{array}$ & $\begin{array}{r}102.5 \\
\pm 0.8 \mathrm{~b}\end{array}$ & $\begin{array}{c}867.4 \\
\pm 1.7 \mathrm{c}\end{array}$ & $\begin{array}{r}792.7 \\
\pm 0.3 \mathrm{c} \\
\end{array}$ \\
\hline Cina 1000 & $\begin{array}{r}106.6 \\
\pm 0.8 \mathrm{a}\end{array}$ & $\begin{array}{c}86.8 \\
\pm 0.9 \mathrm{c}\end{array}$ & $\begin{array}{c}971.7 \\
\pm 2.4 \mathrm{~d}\end{array}$ & $\begin{array}{c}857.6 \\
\pm 2.3 \mathrm{~d}\end{array}$ \\
\hline
\end{tabular}

a, b, c, d: Significant difference $(\mathrm{P}<0.01)$ by ANOVA (one way) in a column.

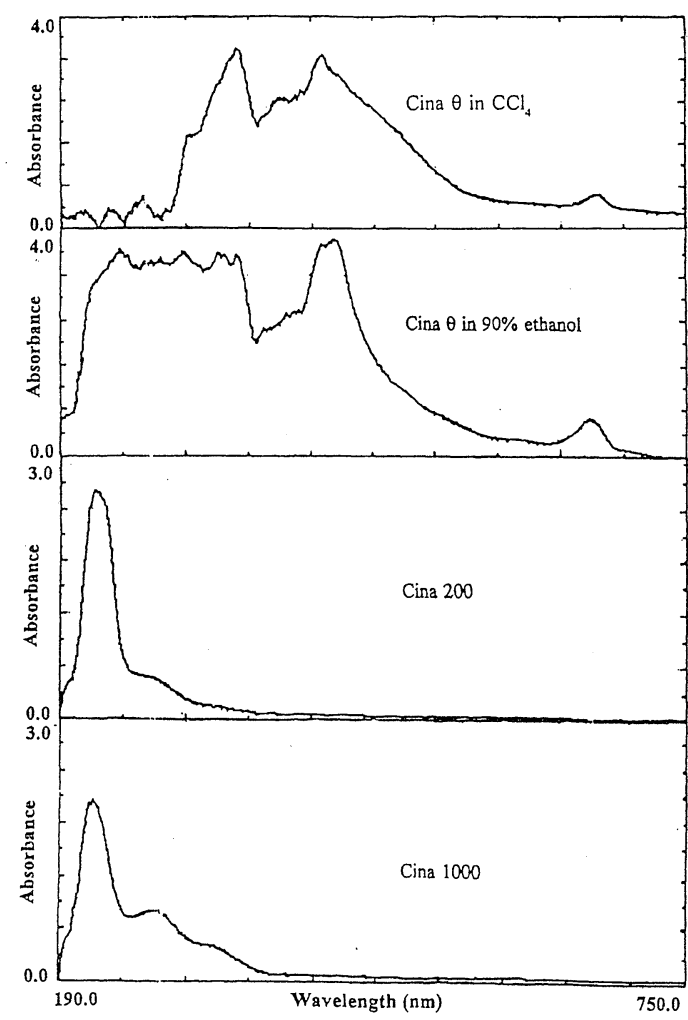

Figure 2 Absorption spectra of Cina $\theta$ (ethanol extract of flowering meristems of $A$. nilagirica) and its two ultra high dilutions called Cina 200 and Cina 1000 , all in 90\% ethanol in wavelength range of 190-750 nm. The same of Cina $\theta$ in $\mathrm{CCl}_{4}$ showing a red shift as compared to Cina $\theta$ in $90 \%$ ethanol. Cina 200 and Cina 1000 show a blue shift. The absorbance intensities in all the 4 are fairly comparable.

calculated in subsequent samples. The $\mathrm{mf}$ density showed marked reduction in the treated dogs. The maximum reduction was $78.4 \%$ with Cina $\theta, 63.1 \%$ with Cina 200 and $71.40 \%$ with Cina 1000 . The reduction was $42.4-64.2 \%$ on the last day of sampling i.e. day 75 (Fig. 1).

\section{Electronic spectra}

Electronic spectra of Cina $\theta$ in $90 \%$ ethanol, Cina $\theta$ in $\mathrm{CCl}_{4}$, Cina 200 and Cina 1000 are given in Fig. 2. The absorption spectra of Cina $\theta$ in ethanol shows a blue shift as compared to that of Cina $\theta$ in $\mathrm{CCl}_{4}$ (Fig. 2). Absorption spectra of Cina 200 and Cina 1000 show a blue shift as compared to Cina $\theta$ in ethanol. The absorbance was fairly comparable in the tincture and its two potencies (Fig. 2). 


\section{NMR Spectra}

The $\mathrm{T}_{1}$ values with S.E. of ${ }^{2} \mathrm{H}$ of water, $\mathrm{OH}, \mathrm{CH}_{2}$ and $\mathrm{CH}_{3}$ of $90 \%$ ethanol, Cina $\theta$ in $90 \%$ ethanol, Cina 200 and Cina 1000 are presented in Table 2 . The $T_{1}$ values were compared by ANOVA. $\mathrm{T}_{1}$ of $\mathrm{OH}$ of water was lowest with Cina $\theta$ and highest with Cina 200. $\mathrm{T}_{1}$ of ethanol hydroxyl was absent in Cina $\theta$, highest in $90 \%$ ethanol and lowest in Cina 1000. $\mathrm{T}_{1}$ of $\mathrm{CH}_{2}$ was highest in Cina 1000 followed by Cina $\theta$, Cina 200 and $90 \%$ ethanol. $\mathrm{T}_{1}$ of $\mathrm{CH}_{3}$ was highest in Cina 1000. This was followed by $90 \%$ ethanol, Cina 200 and Cina $\theta$ in decreasing order (Table 2).

\section{DISCUSSION}

It is evident from the results that both the crude extract as well as the two potencies of $A$. nilagirica proved highly effective against the microfilariae of Dirofilaria immitis in dogs. Species of Artemisia are reported to contain various types of essential oils and sesqueterpene lactones including santonin (Carnat et al., 1992; Rucker et al., 1992; Nin et al., 1995; Todorrova and Krasteva, 1996). These compounds in the crude extract may have a direct effect on the microfilariae. The effect of the two potencies, which have no drug molecules, can be explained in a different way. Electronic spectra of Cina $\theta$ in $90 \%$ ethanol and that in $\mathrm{CCl}_{4}$ are different with the former showing a blue shift as compared to the latter. This suggests molecular complexation and charge transfer (CT) interaction between the compounds of $A$. nilagirica and ethanol molecules. Here ethanol molecules served as electron donors and Artemisia compounds as electron acceptors (Singh and Dikshit, 1995). Alcohols donate electrons from the highest occupied nonbonding, $\mathrm{n}\left(\mathrm{b}_{1}\right)$, orbital of the Oxygen atom to the $\pi$ orbital of the acceptors in Artemisia (Frey et al., 1994). Absorption occurs well into the near UV region. CT is further evidenced by the absence of $T_{1}$ value at the ethanolic hydroxyl site of Cina $\theta$ (Table 2). Relaxation at this site was too efficient and the n.m.r. signal was too broad to be observed (Banwell and McCash, 1994). We have already observed CT interaction in other potentized homoeopathic drugs like Iodine and Nux vomica (Sukul, 1999). Other plant extracts such as tea contain a mixture of potential complexing agents which form molecular complexes with other compounds (Hernaez et al., 1997). For intermolecular electron-transfer systems, a number of competing acceptors may exist, as in Artemisia extract, in a complicated spatial array about the donor. The back transfer process is coupled to the forward transfer in a complex fashion (Weidemaier and Fayer, 1996). Thus the electronic configuration of the donor molecules, i.e. aqueous ethanol, would undergo a change according to the nature of the electronic acceptors of Artemisia extract. With successive dilution, the acceptor molecules are progressively depleted and fresh molecules of the donor occupy their place. Finally, it is the molecules of aqueous ethanol which exist in the form of ethanol molecules surrounded by the hydration shell of water molecules.

UV spectroscopy is highly sensitive to the distortion of chromophores and auxochromes (Banwell and McCash, 1994). The UV spectra of Cina 200 and Cina 1000 show a blue shift as compared to that of Cina $\theta$ thereby suggesting a possible change in the electronic configuration of the medium, i.e. aqueous ethanol (Fig. 2). The altered $T_{1}$ values of the deuterium nuclei of Cina 200 and Cina 1000 as compared to those of aqueous ethanol and Cina $\theta$ (Table 2) suggest that the rate of tumbling in the relevant parts of the molecule in potentized Cina has undergone a change obviously due to CT interaction and mechanical agitation (Sukul, 1999). Haseba et al. (1993) reported that the thermal motion of water molecules in sonicated aqueous ethanol was greater than that in unsonicated one, and this change in the solution structure produced significant biological effects.

Living microfilariae of $D$. immitis, injected intravenously, disappeared rapidly from the peripheral circulation of uninfected dogs, which had received and cleared previous infections of microfilariae. Eosinophilia and antibodies to microfilaria were demonstrable in the blood of the dogs (Wong, 1964, 1966 cited by Wong and Guest, 1969). Filarial worms are known to cause immunosuppression (Ottesen, 1980). It is possible that potentized Cina might have removed immunosuppression resulting in vigorous responsiveness of the host to parasite antigens thereby clearing microfilariae from the blood.

\section{ACKNOWLEDGEMENT}

We are thankful to the Director, Sophisticated Instruments Facility, Indian Institute of Science, Bangalore for providing the NMR data of the samples. The electronic spectra of the samples were obtained through the courtesy of Professor Shelley Bhattacharyya and her research scholar Sm. Rakhi Ghosh of our department. 


\section{REFERENCES}

1) Anonymous (1920): The American Homoeopathic Pharmacopoeia, 9th ed., Boericke and Tafel, Philadelphia.

2 ) Banwell, C.N. and McCash, E. (1994): Fundamentals of molecular spectroscopy, 4th ed., Tata Mc Graw Hill Publishing Company Ltd., New Delhi.

3 ) Boericke, W. (1927): Pocket Manual of Homoeopathic Materia Medica. Indian ed. (1976). Sett Dey, Calcutta.

4 ) Carnat, A.P., Madesclaria, M. and Chavignon, O. (1992): Cis-Chrysanthenol, a main component in essential oil of Artemisia absinthium L. growing in Average (Massif Central), France. J. essent. oil res., 4, 487-490

5 ) Frey, J.E., Aiello, T., Beaman, D.N., Combs, S.D., Fu, Shi-lin and Puckett, J.J. (1994): Charge transfer complexes of tetracyanoethylene with alkyl, alkenyl, and aryl derivatives of Oxygen. J. Org. Chem., 59, 1817-1830

6 ) Haseba, T., Matsushita, K., Asakura, T., Kameyama, K., Tamaki, T., Okouchi, S., Watanabe, T. and Uedaira, H. (1993): Diminution of biological reactivity of ethanol by changing the solution structure by weak ultrasonication. Alcohol. Clin. Exp. Res., 17, 963-967

7 ) Hernaez, J. Meirong, Xu and Daswood, R. (1997): Effects of tea and chlorophyllin on the mutagenicity of $\mathrm{N}$-Hydroxy-IQ: Studies on enzyme inhibition, molecular complex formation, and degradation/scavenging of the active metabolites. Environ. Mol. Mutagen, 30, 468-474

8 ) Kent, J.T. (1911): Homoeopathic Materia Medica. Indian ed. (1962), Sett Dey, Calcutta.

9 ) Nin, S., Arfailoi, P. and Boretto, M. (1995): Quantitative determination of some essential oil components of selected Artemisia absinthium plants. J. essent. oil res., 7, 271-277

10) Ottesen, E.A. (1980): The clinical spectrum of lymphatic filariasis and its immunological determinants.
WHO/FIL/80, 160-168

11) Rucker, G., Manns, D. and Wallbert, S. (1992): Homoditerpene peroxides from Artemisia absinthium. Phytochemistry, 31, 340-342

12) Sanders, J.K.M. and Hunter, B.K. (1993): Modern NMR Spectroscopy. Oxford University Press, Oxford.

13) Singh, P.R. and Dikshit, S.K. (1995): Molecular Spectroscopy, principles and chemical applications. S. Chand and Co. Ltd., New Delhi.

14) Singh, U., Wadhwan, A.M. and Johri, B.M. (1983): Dictionary of economic plants in India, 2nd ed., ICAR, New Delhi.

15) Sukul, N.C. (1997): High Dilution Pharmacology and Homoeopathy. A. Sukul, Santiniketan, West Bengal.

16) Sukul, N.C. (1999): Electron transfer interaction retains molecular specificity of drugs at ultra high dilutions. Environ. Ecol. (in press)

17) Sukul, N.C. and Klemm, W.R. (1988): Influence of dopamine agonists and an opiate antagonist on Agaricus induced catalepsy, as tested by a new method. Arch. Int. Pharmacodyn. Ther., 295, 40-51

18) Sukul, N.C., Ghosh, S. and Sinhababu, S.P. (1996): Dose dependent suppression of haloperidol induced catalepsy by potentized Agaricus muscarius. Br. Hom. J., 85, 141144

19) Todorrova, M.N. and Krasteva, M.L. (1996): Sesqueterpene lactones from Artemisia lerchina. Phytochemistry, 42, 1231-1233

20) Weidemaier, K. and Fayer, M.D. (1996): Role of diffusion in photoinduced electron transfer on a micelle surface: theoretical and Monte Carlo investigations. J. Phys. Chem., 100, 3767-3774

21) Wong, M.M. and Guest, M.F. (1969): Filarial antibodies and eosinophilia in human subjects in endemic area. Trans. Roy. Soc. Trop. Med. Hyg., 63, 796-800 